\title{
AORTIC VALVE INSUFFICIENCY AND CEREBRAL "STEAL” DURING PEDIATRIC CARDIOPULMONARY BYPASS
}

Rosendo A. Rodriguez, MD, PhD, ${ }^{\text {a }}$ Garry Cornel, MBBS, FRCSC, ${ }^{\text {a }}$ Nihal Weerasena, MBBS, FRCS(CTh), ${ }^{\mathrm{a}}$

Martin C. Hosking, MD, FRCPC, ${ }^{\mathrm{b}}$ Kimmo Murto, MD, FRCPC, ${ }^{\mathrm{c}}$ and Joe Helou, MD, ${ }^{\mathrm{a}}$ Ottawa, Ontario, Canada

Systemic arterial flow patterns associated with diastolic runoff usually result in reversal of flow in the aorta and carotid arteries. ${ }^{1,2}$ Such hemodynamic conditions are seen with large ductus arteriosus and systemic to pulmonary artery shunts. ${ }^{1,2}$ When the condition is evaluated by transcranial Doppler (TCD), these changes are reflected in the absence of diastolic flow in the brain circulation. ${ }^{2,3}$ Severe aortic insufficiency produces similar physiologic changes that are characterized by the presence of diastolic runoff into the left ventricle,${ }^{4}$ producing "steal" from the carotid arteries. Although it appears that the degree of aortic regurgitation correlates with the severity of the altered Doppler flow, ${ }^{4}$ its implications on brain function, particularly during cardiopulmonary bypass (CPB), are unknown.

Brain monitoring, including electroencephalography, TCD, and regional cerebral mixed venous oxygen saturation (rCVOS), have been previously applied to pediatric cardiac operations to detect brain dysfunction during venous cannulation. ${ }^{5}$ This report describes a pediatric case of aortic valve replacement for severe aortic insufficiency, in which brain monitoring detected severe cerebral "steal" on the initiation of CPB and subsequently influenced the management of the patient's condition.

A 7-year-old girl $(22.3 \mathrm{~kg})$, who was followed since infancy because of aortic valve stenosis (transvalvular gradient, 65 $\mathrm{mm} \mathrm{Hg}$ ) underwent transcatheter valve dilatation. A TCD system (Nicolet, Madison, Wis), secured on the temporal window, noninvasively monitored mean, peak, and end-diastolic cerebral blood flow velocity (CBFV) from the right middle cerebral artery (depth, $50 \mathrm{~mm}$ ). The angiogram showed the left aortic arch with a normal branching pattern, bicuspid aortic valve $(17 \mathrm{~mm})$, and mild left ventricular dilatation. A $15 \mathrm{~mm} \times 4 \mathrm{~cm}$ balloon catheter (NuMed, Cornwall, Ontario, Canada) was used to dilate the aortic valve, resulting in the

From the Division of Cardiovascular Surgery, Department of Surgery, ${ }^{\mathrm{a}}$ Division of Cardiology, Department of Paediatrics, ${ }^{\mathrm{b}}$ and Department of Anaesthesia, ${ }^{c}$ the Children's Hospital of Eastern Ontario, Ottawa, Ontario, Canada.

Received for publication Nov 3, 1998; accepted for publication Nov 11, 1998.

Address for reprints: Rosendo A. Rodriguez, MD, Division of Cardiovascular Surgery, Department of Surgery, Children's Hospital of Eastern Ontario, 401 Smyth Rd, Ottawa, ON K1H 8L1, Canada.

J Thorac Cardiovasc Surg 1999;117:1019-21

Copyright (C) 1999 by Mosby, Inc.

$0022-5223 / 99 \$ 8.00+0 \quad \mathbf{1 2 / 5 4 / 9 5 9 2 5}$ resolution of the stenosis but moderate (grade 2-3) residual aortic insufficiency. ${ }^{4}$ The peak, mean, and diastolic CBFV before catheter dilatations were 59,48 , and $39 \mathrm{~cm} / \mathrm{s}$, respectively (mean arterial pressure [MAP], $60 \mathrm{~mm} \mathrm{Hg}$ ). Although CBFV returned to predilatation values immediately after the first 2 attempts, the diastolic CBFV disappeared $(0 \mathrm{~cm} / \mathrm{s})$ at the end of the last dilatation (MAP, $62 \mathrm{~mm} \mathrm{Hg}$ ), indicating middle cerebral artery runoff secondary to the aortic insufficiency (Fig 1).

In the following year her exercise tolerance deteriorated because of worsening insufficiency (grade 4), and it was decided that she should undergo an aortic valve replacement. During the operation, in addition to TCD monitoring, a 16channel Grass machine (Grass, Quincy, Mass) recorded, filtered (bandpass, 1-70 Hz), and printed the electroencephalography using scalp-surface electrodes from homologous frontocentral, centro-occipital, frontotemporal, and temporooccipital locations. A near-infrared spectrophotometry (INVOS 3100; Somanetics, Troy, Mich) was applied on the right forehead (receivers, 30 and $40 \mathrm{~mm}$ ) to monitor the rCVOS throughout the operation. The MAP, heart rate, hematocrit, systemic arterial oxygen saturations, end-tidal carbon dioxide, inspired oxygen fraction $\left(\mathrm{FIO}_{2}\right)$, central venous pressure (CVP), electrocardiogram, and temperature were also monitored.

After a narcotic-based induction, maintenance of anesthesia was achieved by a balanced technique with sufentanil ( 0.3 $\mu \mathrm{g} / \mathrm{kg} / \mathrm{hr}$ ) and isoflurane (end-tidal, $0.8 \%$ ). During CPB, the volatile agent was replaced by propofol infusion (30-166 $\mu \mathrm{g} / \mathrm{kg} / \mathrm{min}$ ). At the beginning of the operation, the peak and mean CBFV were 88 and $39 \mathrm{~cm} / \mathrm{s}$, respectively, without diastolic flow (MAP, $62 \mathrm{~mm} \mathrm{Hg}$ ), rCVOS of $75 \%\left(\mathrm{FIO}_{2}, 35 \%\right)$, systemic arterial oxygen saturations of $100 \%, \mathrm{CVP}$ of $7 \mathrm{~mm}$ $\mathrm{Hg}$, and hematocrit of $31 \%$. The electroencephalography before and at initial CPB demonstrated a diffuse bifrontal dominant high-frequency activity intermixed with slower frequency waves as a result of the opioid and volatile anesthesia (Fig 2). Within the first 3 minutes of the initiation of $\mathrm{CPB}$ (flow, $2.0 \mathrm{~L} / \mathrm{min}$ ), the MAP and rCVOS decreased to $23 \mathrm{~mm}$ $\mathrm{Hg}$ and $54 \%$, respectively, as compared with pre-CPB values of $51 \mathrm{~mm} \mathrm{Hg}$ and $72 \%$, suggesting cerebrocortical mixed venous desaturation $\left(\mathrm{FIO}_{2}, 40 \%\right.$; hematocrit, $18 \%$; temperature, $34.5^{\circ} \mathrm{C}$; CVP, $4 \mathrm{~mm} \mathrm{Hg}$ ). At this time, retrograde diastolic flow was evident by TCD; and the peak, mean, and diastolic CBFV decreased to 66,25 , and $-30 \mathrm{~cm} / \mathrm{s}$, respectively (Fig 1). The diastolic flow reversal was associated with increased cerebral "steal" because systemic hypotension presumably decreased cerebral perfusion pressure. The elec- 
A

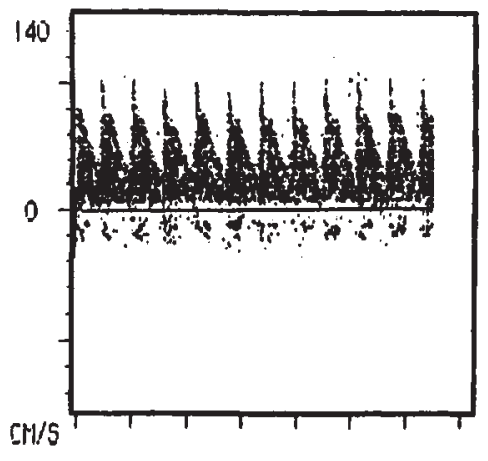

C

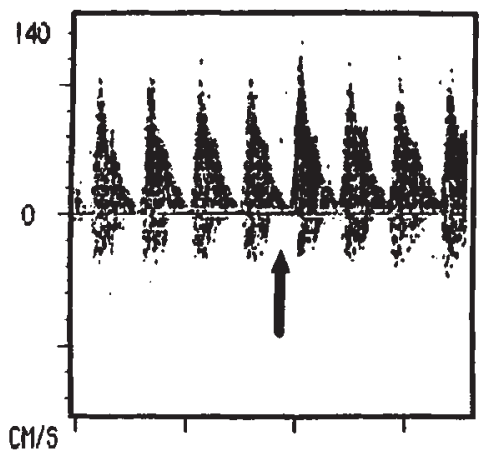

B

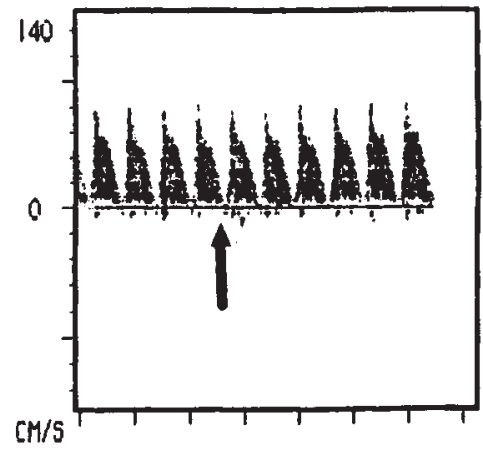

D

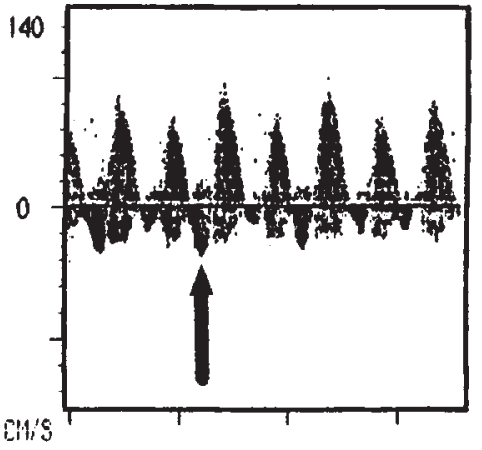

Fig 1. TCD waveforms recorded before $(\mathbf{A})$ and after $(\mathbf{B})$ residual aortic valve insufficiency during transcatheter valve dilatation. Absence of diastolic Doppler flow was identified in $(\mathbf{B})$ and during surgery before CPB $(\mathbf{C})$. The severe systemic hypotension after institution of CPB (D) resulted in retrograde diastolic Doppler flow (arrow).

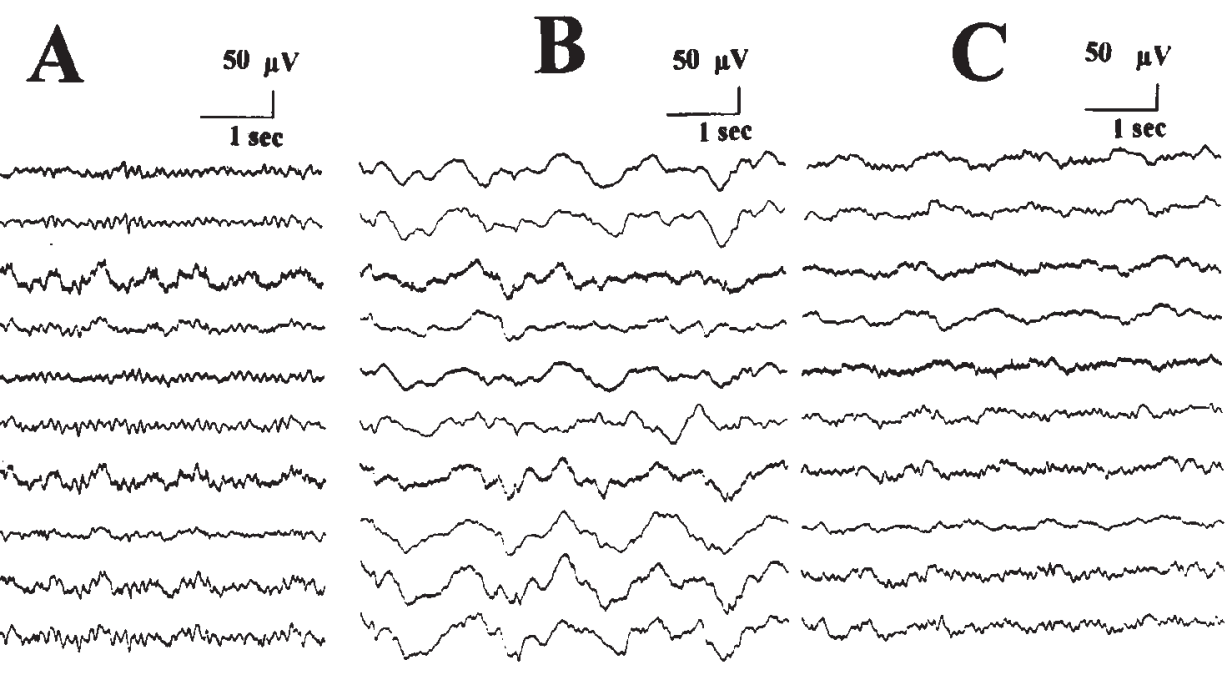

Fig 2. Electroencephalographic activity recorded as follows: $(\mathbf{A})$ at initial $\mathrm{CPB},(\mathbf{B})$ in the presence of cerebral retrograde diastolic Doppler flow and dysfunctional electrocardiogram, and $(\mathbf{C})$ during mild hypothermia (temperature, $\left.32 \cdot 1^{\circ} \mathrm{C}\right)$. 
troencephalography became severely slow as delta waves were distributed throughout all derivations (Fig 2), and the electrocardiogram showed ST changes that implied myocardial ischemia. The concern for brain and myocardial protection as a result of cerebral and coronary "steal" led to the decision to immediately initiate cooling. Core temperature was reduced to $30.6^{\circ} \mathrm{C}$. Within the next 8 minutes (flow, 2.6 $\mathrm{L} / \mathrm{min}$ ), rCVOS gradually increased to $72 \%$.

Although TCD alterations persisted from initial cooling to the time the aorta was clamped (MAP, $32 \mathrm{~mm} \mathrm{Hg}$; heart rate, 74 beats/min; $\mathrm{FIO}_{2}, 31 \%$ ), the electroencephalogram and electrocardiogram gradually improved under hypothermia. The diastolic TCD flow changes ceased at aortic crossclamping (temperature, $26.9^{\circ} \mathrm{C} ; \mathrm{rCVOS}, 74 \%$ ). After the operation, no neurologic complications were detected, and the patient made an unremarkable recovery.

Discussion. The balance between cerebral perfusion pressure and vascular resistance may be altered during aortic valve insufficiency. Cerebral vascular resistance falls in an attempt to diminish the severity of the diastolic runoff. ${ }^{3}$ When the brain is unable to compensate for these effects, absence of diastolic forward flow is present in the intracranial circulation. ${ }^{2,3}$ In our case, the cerebral effects of aortic insufficiency from transcatheter dilatation were immediately detected by the absence of diastolic flow via the TCD. Later, the systemic hypotension resulting from the initiation of $\mathrm{CPB}$ presumably decreased cerebral perfusion pressure to a critical level to result in cerebral diastolic retrograde flow. This Doppler "sign" and the accompanying electrocardiographic ischemic changes were suggestive of severe "steal" from the cerebral and coronary arteries. The impact of these brain perturbations were further supported by the associated cerebral vascular desaturation and electroencephalographic slowing indicative of brain dysfunction. ${ }^{5}$ Improvement of these physiologic indicators by cooling suggests that mild hypothermia should be used in the early stages of CPB if severe cerebral "steal" is detected, to minimize the systemic effects of this aortoventricular shunting. In addition, higher systemic blood pressures would optimize cerebral and coronary blood flow. Although the implications on postoperative outcome of these physiologic changes are unknown, this case illustrates the importance of using indicators of brain function during pediatric cardiac operations. In the presence of cardiac lesions associated with increased diastolic runoff, a cerebral "steal" phenomenon can exist, which may be greatly exacerbated by the physiologic changes during $\mathrm{CPB}$.

\section{REFERENCES}

1. Serwer GA, Armstrong BE, Anderson PAW. Noninvasive detection of retrograde descending aortic flow in infants using continuous wave Doppler ultrasonography: implications for diagnosis of aortic run-off lesions. J Pediatrics 1980;97:394-400.

2. Serwer GA, Armstrong BE, Sterba RJ, Anderson PAW. Alterations in carotid arterial velocity-time profile produced by the Blalock-Taussig shunt. Circulation 1981;63:1115-20.

3. Perlman JM, Hill A, Volpe JJ. The effect of patent ductus arteriosus on flow velocity in the anterior cerebral arteries: ductal steal in the premature newborn infant. J Pediatrics 1981;99:767-71.

4. Tani LY, Minich LL, Day RW, Orsmond GS, Shaddy RE. Doppler evaluation of aortic regurgitation in children. Am J Cardiol 1997;80:927-31.

5. Rodriguez RA, Cornel G, Semelhago L, Splinter WM, Weerasena NA. Cerebral effects in superior vena caval cannula obstruction: the role of brain monitoring. Ann Thorac Surg 1997:64:1820-2. 